\title{
A Genetic and Biochemical Analysis of the Role of Gluconeogenesis in Sporulation of Saccharomyces cerevisiae
}

\author{
By J. RICHARD DICKINSON* AND ANTHONY S. WILLIAMS \\ Department of Microbiology, University College, Cardiff CF2 1TA, UK
}

(Received 1 April 1986)

\begin{abstract}
The requirement for gluconeogenesis and the pentose phosphate pathway in sporulation of Saccharomyces cerevisiae was investigated using homozygous diploids with mutations in selected portions of the respective metabolic pathways. Mutations affecting the genes $F B A I$ (fructose1,6-bisphosphate aldolase), GPMI (phosphoglycerate mutase) and ZWFI (glucose-6-phosphate dehydrogenase) were used. Homozygous diploids bearing either $f b a 1-11$ or gpml mutations were asporogenous, indicating an absolute requirement for gluconeogenesis in sporulation. A strain homozygous for the $z w f l$ mutation sporulated, but at a reduced level compared to the wild-type. Homozygous spd $1-1$ mutations restored the ability to sporulate in $f b a 1-11$ homozygous diploids; this is believed to occur as a consequence of reduced $\mathrm{NH}_{4}^{+}$levels in spd1-1-bearing strains, the reduced intracellular $\mathrm{NH}_{4}^{+}$content serving to promote gluconeogenesis via the residual low levels of enzyme activity present in such mutants.
\end{abstract}

\section{INTRODUCTION}

Diploid strains of Saccharomyces cerevisiae can undergo a switch from vegetative growth and mitosis to the alternative developmental pathway of meiosis and sporulation. This switch is dependent on the presence of two alleles at the mating-type locus MATa and MAT $\alpha$, can only occur during the $\mathrm{G} 1$ phase of the cell cycle, and is subject to regulation by nutritional conditions (Esposito \& Klapholz, 1981). Typical conditions to effect sporulation include the use of a poorlyutilized carbon source such as acetate, and the absence of nitrogen, for $\mathrm{NH}_{4}^{+}$in particular is a very strong repressor of sporulation (Esposito \& Klapholz, 1981).

Previous studies aimed at characterizing the metabolic changes that occur in sporulation showed that conditions leading to initiation of sporulation involve a rapid change in the operation of the tricarboxylic acid and glyoxylate cycles such that the intracellular concentration of glutamate increases (Dickinson et al., 1983, 1985). At about $4 \mathrm{~h}$ net glutamate synthesis ceased and trehalose synthesis was initiated via glyoxylate cycle derived intermediates. Subsequently fatty acid synthesis began, concomitant with onset of operation of the pentose phosphate pathway (Dickinson et al., 1983). The aim of the present work was to further investigate the role of gluconeogenesis and the pentose phosphate pathway in the metabolism of sporulation. The approach was to use homozygous diploids with mutations in representative portions of the respective metabolic pathways. On the whole gluconeogenesis is merely glycolysis in reverse, though there are of course certain irreversible enzymic steps unique to glycolysis or gluconeogenesis. For example, phosphofructokinase is used solely in glycolysis: fructose-1,6bisphosphatase catalyses this step in gluconeogenesis (Fraenkel, 1982). Numerous isolations have been made in different laboratories of mutants affected in various functions affecting glycolysis, gluconeogenesis and the pentose phosphate cycle. Very often the answers that were sought were biochemical in nature, and sporulation was not considered. However, it is known for example that homozygous diploids with mutations in all three of the genes $H X K 1$ (hexokinase P1), $H X K 2$ (hexokinase P2) and $G L K 1$ (glucokinase) are asporogenous (Maitra \& Lobo, 1983), whereas diploids homozygous for the pykl mutation (which results in a defective 
pyruvate kinase) sporulate well (Sinha \& Maitra, 1977). Undoubtedly, workers in many laboratories have experienced difficulty in sporulating most glycolysis or gluconeogenesis mutants when doing routine strain constructions with such mutants. Because we believe we understand some of the important metabolic aspects of sporulation it was felt that it was possible to predict which mutations should result in asporogeny and which should not. For example, pyruvate kinase is not required in gluconeogenesis as this step is bypassed by phosphoenolpyruvate carboxykinase. Thus, one would expect pykl homozygous diploids to be able to sporulate.

In order to test our hypothesis about the crucial role of gluconeogenesis and the pentose phosphate pathway in sporulation this study used homozygous diploids affected in the following genes: $Z W F I$ (glucose-6-phosphate dehydrogenase), the first enzyme of the oxidative portion of the pentose phosphate pathway (Lobo \& Maitra, 1982a); FBAl (fructose-1,6-bisphosphate aldolase, required in glycolysis and gluconeogenesis; Lobo, 1984), and GPM1 (formerly known as ' $P G M 1$ ') (phosphoglycerate mutase, required in glycolysis and gluconeogenesis; Lam \& Marmur, 1977). In addition, we examined the effect of homozygous spd1 mutations, for it had been noted during strain construction that inclusion of this mutation, which confers derepression of sporulation as well as resistance to $\mathrm{NH}_{4}^{+}$repression of sporulation (Vezinhet $e t$ al., 1979; Dickinson \& Dawes, 1983), resulted in the sporulation of strains homozygous for glycolysis or gluconeogenesis mutations which were otherwise asporogenous.

\section{METHODS}

Yeast strains. The strains used in this study are described in Table 1. Strain 59.4A was derived from S41 by UV mutagenesis, selected by an ether selection technique (Dawes \& Hardie, 1974) and redissected to yield the homothallic diploid segregant as described by Dickinson \& Dawes (1983). Strain 275.5D, which is homozygous for the gdhl-6 mutation (a nonsense mutation in the structural gene for NADP ${ }^{+}$-dependent glutamate dehydrogenase), was described by Dickinson \& Dawes (1983). Diploid strains 19.2.1, 12.2.1 and T2 were constructed from the parental strains $\mathrm{T} 45 \mathrm{C}, \mathrm{T} 1 \mathrm{~A}$ and $8 / 30$ respectively using conventional yeast genetic techniques (Mortimer \& Hawthorne, 1975). Diploid strain 11.1.5 was constructed by crossing T45C to spores of 59.4A and isolating the homothallic diploid segregant. All strains were cloned before use.

Growth and sporulation of cells. Cells were grown with shaking at $25^{\circ} \mathrm{C}$ in conical flasks filled to $40 \%$ total volume in a liquid YEPGE medium, as this was the only medium that supported growth of all of the strains. This medium contained (per litre): $10 \mathrm{~g}$ yeast extract; $20 \mathrm{~g}$ bacteriological peptone; $30 \mathrm{ml}$ glycerol; $10 \mathrm{ml}$ ethanol; $0.1 \mathrm{~g}$ adenine and $0.1 \mathrm{~g}$ uracil. Before sporulation the cells were grown in YEPGE to a density of $10^{7} \mathrm{cells}^{-1}$. Sporulation was induced by the method of Fast (1973); the sporulation medium contained (per litre) $20 \mathrm{~g}$ potassium acetate and $0.15 \mathrm{~g}$ benzylpenicillin. Growth and sporulation of the various strains was at $25^{\circ} \mathrm{C}$ rather than the more usual $30^{\circ} \mathrm{C}$ because strains bearing $f b a l$ mutations do not grow on alcohol-containing media at $36^{\circ} \mathrm{C}$ (Lobo, 1984), and it was deemed important to ensure there was no temperature-sensitive inhibition of growth.

Assay of intracellular $\mathrm{NH}_{4}$ content. Cells were harvested by filtration using Oxoid 'Nuflow' cellulose acetate membrane filters $\left(0.45 \mu \mathrm{m}\right.$ grade) and fixed in ice-cold $5 \%(\mathrm{w} / \mathrm{v})$ perchloric acid. After $30 \mathrm{~min}$ at $0{ }^{\circ} \mathrm{C}$ the material was centrifuged for $5 \mathrm{~min}$ at $5000 \mathrm{~g}$ and the supernatant was then stored deep-frozen overnight. The following day the thawed supernatants were carefully neutralized using ice-cold dilute potassium hydroxide and potassium perchlorate was removed by centrifugation. The neutralized perchloric acid extracts were frozen to $-78^{\circ} \mathrm{C}$ and lyophilized. The lyophilized material was resuspended in buffer $\mathrm{A}(0.1 \mathrm{M}$-imidazole/ $\mathrm{HCl} \mathrm{pH} 7.9)$ and assayed immediately. The assay mixture contained (in a final volume of $2.8 \mathrm{ml}):$ buffer A $(2.7 \mathrm{ml}) ; \mathrm{NADH}(0.36 \mu \mathrm{mol})$; EDTA $(2.7 \mu \mathrm{mol})$; ADP $(5.1 \mu \mathrm{mol})$ and Boehringer beef liver glutamate dehydrogenase $(20 \mu \mathrm{l}$ enzyme diluted $1: 2000$ immediately before use). This mixture was preincubated at assay temperature $\left(25^{\circ} \mathrm{C}\right)$ for $3 \mathrm{~min}$ before initiating the glutamate dehydrogenase reaction by adding 2 -oxoglutaric acid $(40.8 \mu \mathrm{mol})$ to one cuvette; an equivalent volume of water was added to a reference cuvette. Ammonium acetate was used to construct a standard curve. The rate of reaction was linear under these conditions up to $300 \mu \mathrm{mol} \mathrm{NH}_{4}^{+}$.

Asssay of aldolase activity. Cells were harvested by filtration as described above, and washed with buffer $\mathrm{B}$ (50 mM-potassium phosphate $\mathrm{pH} 7 \cdot 4,2$ mM-EDTA, 2 mM-2-mercaptoethanol). The cells were resuspended in buffer $B$ and broken by agitating the suspension $(3 \mathrm{ml})$ at high speed for $35 \mathrm{~s}$ with an equal volume of 40 -mesh acid-washed glass beads in a Braun homogenizer. The homogenate was decanted from the glass beads and centrifuged at $11600 \mathrm{~g}$ for $15 \mathrm{~s}$. Portions of the resulting supernatant were used immediately as the source of the enzyme. Aldolase was assayed as described by Maitra \& Lobo (1971). 
Table 1. Genotypes and origins of strains used

\begin{tabular}{|c|c|c|}
\hline Strain & Genotype & Origin* \\
\hline S41 & $\frac{M A T \mathbf{a}}{M A T \alpha} \frac{H O}{H O} \frac{\arg 4-1}{\arg 4-1} \frac{c y h 1}{c y h 1}$ & H. O. Halvorson \\
\hline $59.4 \mathrm{~A}$ & $\frac{M A T \mathrm{a}}{M A T \alpha} \frac{H O}{H O} \frac{\arg 4-1}{\operatorname{arg4-1}} \frac{\operatorname{cyhl} 1}{\operatorname{cyhl} 1} \frac{\operatorname{spdl-1}}{\operatorname{spdl-1}}$ & I. W. Dawes \\
\hline 275.5D & $\frac{M A T \mathrm{a}}{M A T \alpha} \frac{H O}{H O} \frac{\text { ade6 }}{\text { ade6 }} \frac{\text { arg } 4-1}{\text { arg4-1 } 1} \frac{\text { cyhl }}{\text { cyh1 } 1} \frac{\text { gdhl-6 }}{\text { gdhl-6 }}$ & This laboratory \\
\hline 19.2.1 & $\frac{M A T \mathrm{a}}{M A T \alpha} \frac{\text { adel }}{\text { ade1 } 1} \frac{\text { ade2 } 2}{\text { ade2 } 2} \frac{\text { arg } 4-1}{A R G 4-1} \frac{\text { trpl } 1}{\text { trpl } 1} \frac{\text { fbal-11 }}{\text { fbal-11 }}$ & This work \\
\hline 11.1 .5 & $\frac{M A T a}{M A T \alpha} \frac{H O}{H O} \frac{\text { adel }}{\text { adel } 1} \frac{\text { ade2 }}{\text { ade } 2} \frac{\arg 4-1}{\arg 4-1} \frac{f b a 1-11}{f b a 1-11} \frac{\text { spdl-1 }}{\text { spdl-1 }}$ & This work \\
\hline 12.2 .1 & $\frac{M A T \mathrm{a}}{M A T \alpha} \frac{\text { metl }}{\text { metl }} \frac{A D E 6}{\text { ade6 }} \frac{L E U 1}{\text { leul }} \frac{z w f 1}{z w f l}$ & This work \\
\hline T2 & $\frac{M A T \mathbf{a}}{M A T \alpha} \frac{\text { ade2 }}{A D E 2} \frac{\mathrm{gpm} 1}{\mathrm{gpml}}$ & This work \\
\hline $\begin{array}{l}\text { T45C } \\
\text { TIA } \\
8 / 30\end{array}$ & $\begin{array}{l}\text { MAT } \alpha \text { adel ade2 trpl lys2 his } 6 \text { fbal-11 } \\
\text { MAT } \alpha \text { ade6 leul metl zwfl } \\
\text { MAT } \alpha \text { ade2 gpm1 }\end{array}$ & $\begin{array}{l}\text { Z. Lobo } \\
\text { P. K. Maitra } \\
\text { P. K. Maitra }\end{array}$ \\
\hline
\end{tabular}

* H. O. Halvorson, Brandeis University, Mass., USA; I.W. Dawes, University of Edinburgh, UK ; Z. Lobo and P. K. Maitra, Tata Institute, Bombay, India.

Table 2. Sporulation of wild-type and mutant strains Sporulation was induced as described in Methods. The values are means \pm SEM of three replicates.

\begin{tabular}{|c|c|c|c|}
\hline \multirow[b]{2}{*}{ Strain } & \multirow{2}{*}{$\begin{array}{l}\text { Relevant } \\
\text { genotype }\end{array}$} & \multicolumn{2}{|c|}{ Sporulation (percentage asci) after } \\
\hline & & $24 \mathrm{~h}$ & $48 \mathrm{~h}$ \\
\hline S41 & Wild-type & $53.5 \pm 3.2$ & $82.5 \pm 4.3$ \\
\hline 59.4A & $\frac{s p d 1-1}{s p d 1-1}$ & $71 \cdot 5 \pm 3.5$ & $86.5 \pm 7.0$ \\
\hline 19.2.1 & $\frac{f b a l-11}{f b a l-11}$ & $0 \pm 0$ & $0 \pm 0$ \\
\hline 11.1 .5 & $\frac{f b a l-11}{f b a l-11} \frac{s p d 1-1}{s p d 1-1}$ & $16 \cdot 5 \pm 2.6$ & $36 \pm 2 \cdot 1$ \\
\hline T2 & $\frac{g p m 1}{g p m l}$ & $0 \pm 0$ & $0 \pm 0$ \\
\hline 12.2.1 & $\frac{z w f 1}{z w f 1}$ & $33 \pm 2 \cdot 8$ & $41 \cdot 5 \pm 3.6$ \\
\hline
\end{tabular}

RESULTS AND DISCUSSION

Table 2 shows sporulation of the wild-type and mutant strains. 59.4A (the sporulationderepressed strain), sporulated more rapidly than the wild-type strain $\mathrm{S} 41$ as judged by the

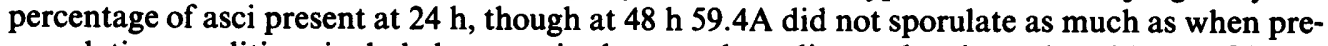
sporulation conditions included acetate in the growth medium, when it produced $95-100 \%$ asci. This was presumably due to the presence of ethanol in the YEPGE pre-sporulation medium as 59.4A hypersporulates when glycerol is the sole carbon source. Strain 19.2.1 (homozygous for the fbal mutation), and strain T2 (homozygous for the gpml mutation) failed to sporulate. These results are consistent with the notion that gluconeogenesis is essential for sporulation. Strain 12.2.1 (homozygous for the $z w f 1$ mutation) sporulated moderately well. This result was 
unexpected since it was believed that $S$. cerevisiae cycles hexose monophosphate produced by gluconeogenesis around the pentose phosphate pathway to produce NADPH, which is required for the reductive biosynthesis of fatty acids that occurs in sporulation shortly after the commencement of gluconeogenesis (Dickinson et al., 1983). Perhaps $z w f 1$ homozygous diploids are forced to use a transhydrogenase to produce NADPH from NADH. This would be energetically less favourable but may be reflected in the fact that the $z w f 1$ homozygous diploid only sporulated to half the extent of the wild-type strain.

A further observation was that although strain 19.2.1 ( $\mathrm{fbal}$ homozygous diploid) failed to sporulate, strain 11.1.5 ( $\mathrm{fbal}$ spdl homozygous diploid) sporulated, albeit not extensively. Thus, homozygous $s p d l$ mutations restored the ability to sporulate in (asporogenous) $f b a l$ homozygous diploids. As mentioned above, this effect has been observed in other glycolysis pathway mutants which also sporulate poorly or not at all. For example, $p f k 1 p f k 2$ homozygous diploids, which are devoid of soluble and particulate phosphofructokinase activities (Lobo \& Maitra, 1982b), sporulate very poorly producing only $1-2 \%$ asci after prolonged incubation with potassium acetate. Likewise, $h x k 1 h x k 2$ glkl homozygous diploids, which lack both hexokinase P1, hexokinase P2 and glucokinase, are asporogenous (Maitra \& Lobo, 1983). However, similar strains which are also homozygous for the spdl mutation sporulate freely (J. R. Dickinson, unpublished results).

There are two kinds of possible explanation for these observations: the SPDI gene product may be a 'regulatory entity' which acts to control directly the level of transcription, translation or activity of enzymes concerned with central aspects of intermediary carbon metabolism; or, restoration of the ability to sporulate may be a secondary consequence of the altered patterns of metabolism which results from the spdl mutation. The present available information favours the latter. The evidence is twofold. A comparison of the activities of a number of glycolysis and gluconeogenesis enzymes in vegetative cells of wild-type (S41) and spd1 homozygous diploids (59.4A) at similar stages of growth in complex medium failed to reveal any significant differences (data not shown). Similarly, a comparison of aldolase specific activity in strains 19.2.1 $\left(\frac{f b a l-11}{f b a l-11}\right)$ and 11.1.5 $\left(\frac{f b a l-11}{f b a l-11} \frac{s p d 1-1}{s p d 1-1}\right)$ in sporulation medium at a time when gluconeogenesis is known to occur did not reveal any significant differences (Table 3). Indeed, strain 11.1.5 had less aldolase specific activity than strain 19.2.1. However, it is known that a major consequence of spdl and spd4 mutations is a reduction in the total cellular 2-oxoglutarate dehydrogenase activity and this enzyme in these strains is also altered in its kinetic properties (Dickinson et al., 1985). Thus, strains bearing spd mutations when in acetate-containing media divert a large proportion of the metabolized carbon out of the tricarboxylic acid cycle to glutamate and other metabolites derived therefrom (Dickinson et al., 1983, 1985). As a result of this excess glutamate synthesis (via the anabolic $\mathrm{NADP}^{+}$-dependent glutamate dehydrogenase) $s p d$ homozygous diploids remove $\mathrm{NH}_{4}^{+}$from both the medium and the cytoplasm; they therefore have a much lower intracellular $\mathrm{NH}_{4}^{+}$content (Table 4) and thereby 'rescue' themselves from $\mathrm{NH}_{4}^{+}$-repression of sporulation.

The present hypothesis as to the way in which $s p d l$ mutations restore the ability to sporulate in strains which are homozygous for mutations affecting gluconeogenesis relies on an understanding of the regulation of carbon metabolism effected by the amount of $\mathrm{NH}_{4}^{+}$available to the cell. It has been known for many years that $S$. cerevisiae cells which were starved of $\mathrm{NH}_{4}^{+}$ accumulate glycogen and trehalose (Trevelyan \& Harrison, 1956), and more recent work has shown that increasing available $\mathrm{NH}_{4}^{+}$stimulates glycolysis (Saita \& Slaughter, 1984). $\mathbf{N H}_{4}^{+}$is therefore antagonistic towards gluconeogenesis but stimulates glycolysis; the stimulation of glycolysis is thought to occur by increasing protein synthetic capacity and thereby increasing energy demand (Saita \& Slaughter, 1984). A reduction of intracellular $\mathrm{NH}_{4}^{+}$such as occurs in spdl mutants would therefore serve to increase gluconeogenic capacity and so increase the ability to sporulate.

The role of the pentose phosphate pathway in the metabolism of sporulation requires further investigation. Current work involves a ${ }^{13} \mathrm{C}-\mathrm{NMR}$ analysis of acetate metabolism in $z w f l$ homozygous diploids, and an examination of whether $S$. cerevisiae possesses an enzyme 
Table 3. Specific activity of aldolase in fbal homozygous diploids

$4 \mathrm{~h}$ atter transfer to sporulation medium cells were harvested and aldolase specific activity was determined as described in Methods. The values are means \pm SEM of three replicates for strain 11.1.5 and four replicates for strain 19.2.1.

\begin{tabular}{|c|c|c|}
\hline Strain & $\begin{array}{l}\text { Relevant } \\
\text { genotype }\end{array}$ & $\begin{array}{l}\text { Aldolase specific activity } \\
\left(\mathrm{nmol} \mathrm{min} \mathrm{mg}^{-1} \mathrm{mg}^{-1}\right)\end{array}$ \\
\hline 19.2.1 & $\frac{f b a 1-11}{f b a 1-11}$ & $6.68 \pm 1.90$ \\
\hline 11.1.5 & $\frac{f b a l-11}{f b a l-11} \frac{s p d 1-1}{s p d 1-1}$ & $4.57 \pm 0.01$ \\
\hline
\end{tabular}

Table 4. Intracellular $\mathrm{NH}_{4}^{+}$content of wild-type and mutant strains in sporulation medium containing $5 \mathrm{~mm}$-ammonium sulphate

$3 \mathrm{~h}$ after transfer to sporulation medium the intracellular $\mathrm{NH}_{4}^{+}$content was determined as described in Methods. Strain 275.5D was included as an internal control; this strain is expected to be low in $\mathrm{NH}_{4}^{+}$as it lacks the anabolic $\mathrm{NADP}^{+}$-dependent glutamate dehydrogenase. The values are means \pm SEM of triplicate determinations.

\begin{tabular}{|c|c|c|}
\hline Strain & $\begin{array}{l}\text { Relevant } \\
\text { genotype }\end{array}$ & $\begin{array}{c}\mathrm{NH}_{4}^{+} \text {content } \\
\text { (nmol per } 10^{6} \text { cells) }\end{array}$ \\
\hline S41 & Wild-type & $27.45 \pm 1.40$ \\
\hline $59.4 \mathrm{~A}$ & $\frac{s p d 1-1}{s p d l-1}$ & $6.88 \pm 0.52$ \\
\hline $275.5 \mathrm{D}$ & $\frac{g d h 1-6}{g d h 1-6}$ & $3 \cdot 20 \pm 0.21$ \\
\hline
\end{tabular}

isofunctional to glucose-6-phosphate dehydrogenase for the utilization of hexose phosphates in the pentose phosphate pathway.

We are grateful to everyone who provided us with strains and especially to $\mathrm{Dr} Z$. Lobo for allowing us to use the aldolase mutant so soon after its initial isolation and characterization. We also thank Professor P. K. Maitra for the helpful and stimulating discussions which prompted this work. Grants from The Science and Engineering Research Council and The University of Wales which enabled Professor Maitra to visit the Laboratory are gratefully acknowledged.

\section{REFERENCES}

DAWES, I. W. \& HARDIE, I. H. (1974). Selective killing of vegetative cells in sporulated yeast cultures by exposure to diethyl ether. Molecular and General Genetics 131, 281-289.

Dickinson, J. R. \& DAWEs, I. W. (1983). Ammonium ion repression of sporulation in Saccharomyces cerevisiae. Journal of General Microbiology 129, 18831888.

Dickinson, J. R., DAwES, I. W., BoYd, A. S. F. \& BAXTER, R. L. (1983). ${ }^{13}$ C NMR studies of acetate metabolism during sporulation of Saccharomyces cerevisiae. Proceedings of the National Academy of Sciences of the United States of America 80, 58475851.

Dickinson, J. R., Ambler, R. P. \& Dawes, I. W. (1985). Abnormal amino acid metabolism in mutants of Saccharomyces cerevisiae affected in the initiation of sporulation. European Journal of Biochemistry 148, 405-406.

EsPosito, R. E. \& KLAPHOLz, S. (1981). Meiosis and ascospore development. In The Molecular Biology of the Yeast Saccharomyces: Life Cycle and Inheritance, pp. 211-287. Edited by J. N. Strathern, E. W. Jones \& J. R. Broach. Cold Spring Harbor, New York: Cold Spring Harbor Laboratory.

FAST, D. (1973). Sporulation synchrony in yeast. Journal of Bacteriology 116, 925-930.

FraENKEL, D. G. (1982). Carbohydrate metabolism. In The Molecular Biology of the Yeast Saccharomyces: Metabolism and Gene Expression, pp. 1-37. Edited by J. N. Strathern, E. W. Jones \& J. R. Broach. Cold Spring Harbor, New York: Cold Spring Harbor Laboratory.

LAM, K.-B. \& MARMUR, J. (1977). Isolation and characterization of Saccharomyces cerevisiae glycolytic pathway mutants. Journal of Bacteriology 130, 746-749.

LoBo, Z. (1984). Saccharomyces cerevisiae aldolase mutants. Journal of Bacteriology 160, 222-226.

LoBo, Z. \& Martra, P. K. (1982a). Pentose phosphate pathway mutants of yeast. Molecular and General Genetics 185, 367-368. 
Lobo, Z. \& MaItra, P. K. (1982b). A particulate phosphofructokinase from yeast. FEBS Letters 137, 279-282.

MaItra, P. K. \& Lobo, Z. (1971). A kinetic study of glycolytic enzyme synthesis in yeast. Journal of Biological Chemistry 246, 475-488.

MaITRA, P. K. \& LoBo, Z. (1983). Genetics of yeast glucokinase. Genetics 105, 501-515.

Mortimer, R. K. \& HaWthorne, D. C. (1975). Genetic mapping in yeast. In Methods in Cell Biology, vol. XI, pp. 221-233. Edited by D. M. Prescott. London: Academic Press.

Saita, M. \& Slaughter, J. C. (1984). Acceleration of the rate of fermentation by Saccharomyces cerevisiae in the presence of ammonium ion. Enzyme and Microbial Technology 6, 375-378.
Sinha, P. \& MaITRA, P. K. (1977). Mutants of Saccharomyces cerevisiae having structurally altered pyruvate kinase. Molecular and General Genetics 158, 171-177.

Trevelyan, W. E. \& Harrison, J. S. (1956). Studies on yeast metabolism. Yeast carbohydrate fractions. Separation from nucleic acid, analysis, and behaviour during anaerobic fermentation. Biochemical Journal 63, 23-33.

VEZINHET, F., KinNaIRD, J. H. \& DAWES, I. W. (1979). The physiology of mutants derepressed for sporulation in Saccharomyces cerevisiae. Journal of General Microbiology 115, 391-402. 